\title{
Cathodoluminescence of Ge- Clusters in Silica Layers
}

\author{
Roushdey Salh", Lena Fitting ${ }^{* *}$, and H.-J. Fitting** \\ *Physics Department, University of Rostock, Universitaetsplatz 3, D-18051 Rostock, Germany \\ **Applied and Engineering Physics, Cornell University, Ithaca NY 14853
}

Scanning transmission electron microscopy (STEM), energy dispersive X-ray analysis (EDX) and cathodoluminescence (CL) have been used to investigate $\mathrm{Ge}^{+}$-implanted amorphous silicon dioxide layers. Commonly, $\mathrm{CL}$ emission spectra of pure $\mathrm{SiO}_{2}$ are identified with particular defect centers within the atomic network of silica including the nonbridging oxygen-hole center (NBOHC) associated with the red luminescence at $650 \mathrm{~nm}(1.9 \mathrm{eV})$ and the oxygen deficient centers (ODC) with the blue $(460 \mathrm{~nm} ; 2.7 \mathrm{eV})$ and ultraviolet UV band $(295 \mathrm{~nm} ; 4.2 \mathrm{eV}),[1]$.

In $\mathrm{Ge}$ doped $\mathrm{SiO}_{2}$ an additional emission band is identified at $(410 \mathrm{~nm} ; 3.1 \mathrm{eV})$, see e.g. [2].

The CL measurements were performed in a Zeiss DSM 960 digital scanning electron microscope equipped with a liquid nitrogen cryogenic stage. The CL is excited by an electron beam energy $\mathrm{E}_{\mathrm{o}}=10 \mathrm{keV}$ and a slightly defocused current $\mathrm{I}_{\mathrm{o}} \approx 600 \mathrm{nA}$ over $100 \times 100 \mu \mathrm{m}$ and collected via a parabolic mirror, a spectrograph $(200-800 \mathrm{~nm})$, and a charge coupled device (CCD) camera, [2].

As samples we have used amorphous, thermally grown $\mathrm{SiO}_{2}$ layers, $500 \mathrm{~nm}$ thick, wet oxidized at $1100{ }^{\circ} \mathrm{C}$ on $\mathrm{Si}$ substrate. The layers are of microelectronic quality and doped by $\mathrm{Ge}^{+}$ions with an energy of $350 \mathrm{keV}$ and a dose of $5 \times 10^{16}$ ions $/ \mathrm{cm}^{2}$ leading to an atomic dopant fraction of about 4 at. $\%$ at a mean depth of about $200 \mathrm{~nm}$, see Fig.1. Afterwards a post-implantation thermal annealing has been performed at temperatures $\mathrm{T}_{\mathrm{a}}=700,900,1100^{\circ} \mathrm{C}$, for 60 minutes in dry nitrogen, [2].

Fig. 2 shows the CL spectra of the $\mathrm{Ge}^{+}$implanted samples annealed at different temperatures $T_{a}$. The large violet emission band at $3.1 \mathrm{eV}$ due to the Ge dopants is observed and the intensity of this peak increases up to a factor of 250 with increasing annealing temperature $T_{a}$ up to $900{ }^{\circ} \mathrm{C}$. Exceeding the annealing temperature to $1100^{\circ} \mathrm{C}$, i.e. to the original oxidation temperature, the CL intensity is reduced again. Thus the thermal annealing process of $\mathrm{Ge}^{+}$implanted layers leads first to a strong increase of the violet luminescence due to formation of low-dimension Ge aggregates like dimers, trimers and higher formation; finally to destruction of the luminescence centers by further growing to Ge nanoclusters. STEM images in cross section technique [3] show the growing in Ge clusters with increasing annealing temperature, see Fig. 3. The nanocluster diameters are growing with annealing temperature from 1-6 nm at $T_{a}=900{ }^{\circ} \mathrm{C}$ to $1-12 \mathrm{~nm}$ at $T_{a}=1100{ }^{\circ} \mathrm{C}$ as shown in Fig. 4. Moreover, due to Ostwald ripening the cluster concentration drops from 4.6 to $2.6 \times 10^{17}$ per $\mathrm{cm}^{3}$. However, their luminescent surfaces or surroundings in their sum have been reduced, i.e. the overall luminescence efficiency decreases.

\section{References}

[1] L. N. Skuja, J. Non-Cryst. Solids 16 (1998) 239.

[2] H. -J. Fitting, T. Barfels, A. N. Trukhin, B. Schmidt, A. Gulans, and A. von Czarnowski J. Non-Cryst. Solids 303 (2002) 218.

[3] L. F. acknowledges support by the Cornell Center for Material Research (IRG-3). 


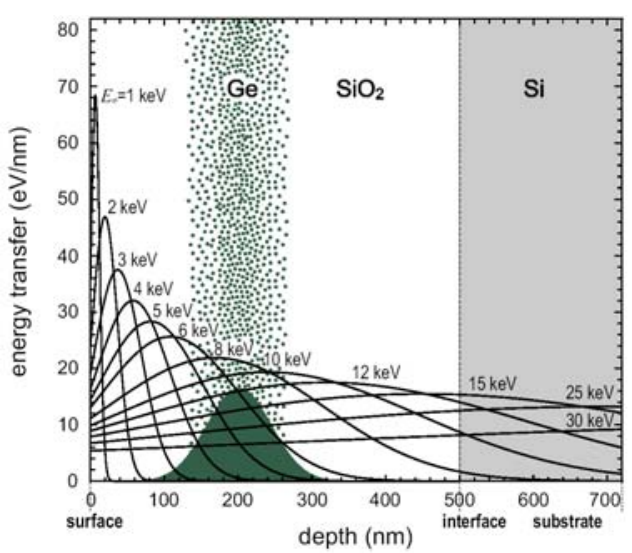

Fig. 1. Electron beam excitation densities in $\mathrm{SiO}_{2}$ layers for different beam energies $E_{o}$ and a $\mathrm{Ge}+$ implanted profile in the mean projected range $R_{p}=200 \mathrm{~nm}$.
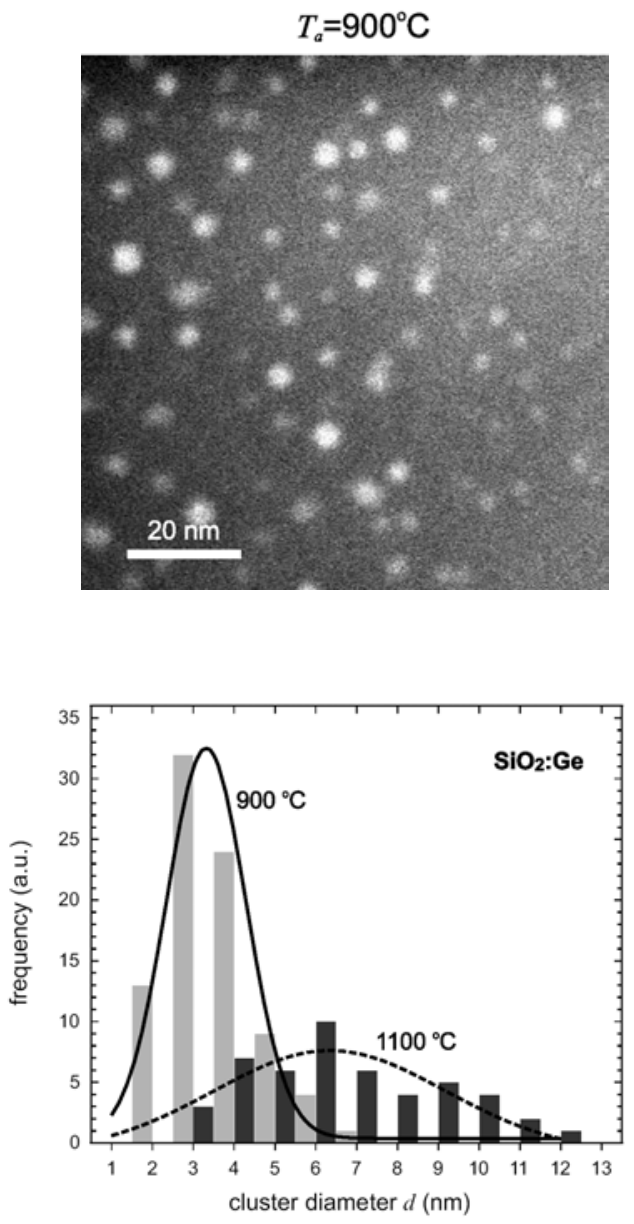

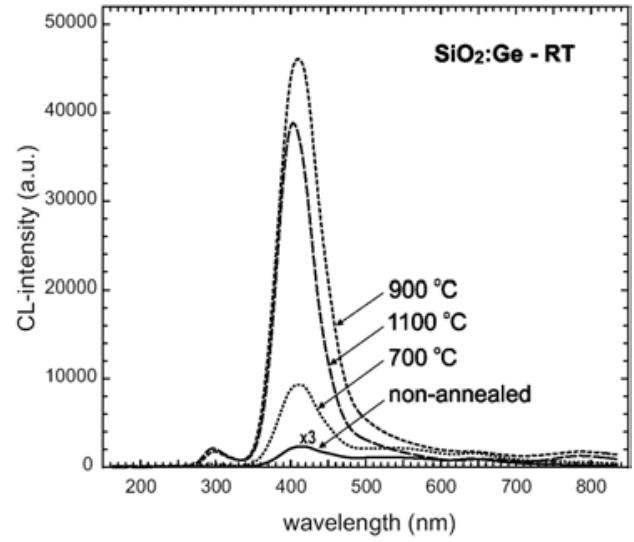

Fig. 2. CL-spectra of thermally annealed $\mathrm{Ge}$ implanted $\mathrm{SiO}_{2}$ layers measured at room temperature (RT); the respective annealing temperatures $T_{a}$ are indicated.

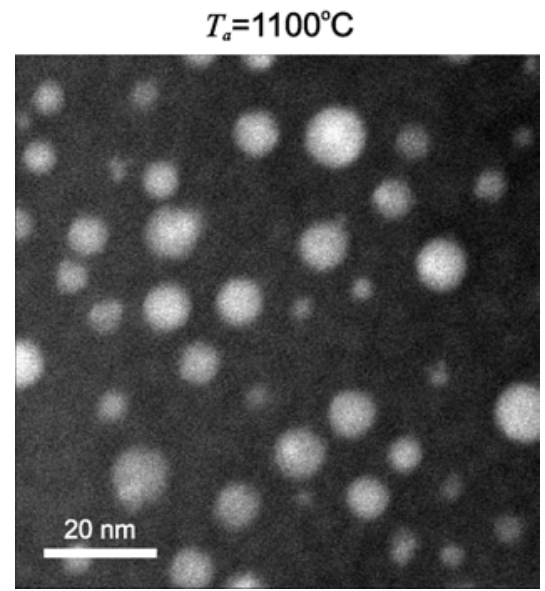

Fig. 3. STEM cross section images of Ge implanted $\mathrm{SiO}_{2}$ layers showing clusters growing (Ostwald ripening) with increasing annealing temperatures $T_{a}$.

Fig. 4. Ge cluster diameter-distributions as a function of the annealing temperature $T_{a}$ : the correlated cluster concentrations are $N_{c}=$ $4.6 \times 10^{17}$ and $2.6 \times 10^{17} \mathrm{~cm}^{-3}$ for $T_{a}=900$ and $1100{ }^{\circ} \mathrm{C}$, respectively. 